Sitientibus Série Ciências Físicas 06: 11-16 (2010)

\title{
Longslit spectroscopy of the peculiar Seyfert 2 galaxy HRG 10103
}

Espectroscopia de Fenda Longa da galáxia peculiar Seyfert 2 HRG 10103

\author{
Paulo C.R. Poppe* e Vera A.F. Martin \\ Departamento de Física / Observatório Astronômico Antares - UEFS \\ Av. Transnordestina, $s / n, k m$ 03, \\ BR 116, Campus da UEFS \\ Feira de Santana - BA - 44036-900
}
Max Faúndez-Abans, Mariângela de Oliveira-Abans, e Iranderly F. de Fernandes Laboratório Nacional de Astrofísica - MCT
R. Estados Unidos, 154, Bairro das Nações
Itajubá - MG - 37504-364

We present the first optical longslit spectroscopy for the galaxy HRG 10103, an Sa(r) type peculiar galaxy seen face-on with an asymmetrical elliptical structure. The main goal of this work is to provide the spectral classification of the current object using the 'traditional' diagnostic diagrams. However, we also present a diagnostic involving the known emissionline ratio $R_{23}$, usually used to estimate the $O / H$ abundance ratio. The idea is to make a better distinction between the narrow-line AGNs and the $\mathrm{H}$ II galaxies. The spectra were obtained in two observatories (OPD-LNA/MCT and Gemini-South) and includes some of the most important emission lines for ionization diagnostic. Based on the observed spectra, HRG 10103 is a Seyfert 2 galaxy with typical line-ratios values in the optical range. We have estimated nuclear redshift of $z=0.039$. The resulting reddening values as a function of distance from the nucleus are presented too. The errors in the fluxes were mostly caused by uncertainties in the placement of the continuum level. The rotation curve is typical of spiral disks, rising shallowly and flattening at an observed amplitude of about $200 \mathrm{~km} \mathrm{~s}^{-1}$. Some other physical parameters have been derived whenever possible. The spectroscopic data reduction was carried out using the GEMINI.GMOS package as well as the standard IRAF procedures.

Key-words: Longslit Spectroscopy, Peculiar Galaxy, Spectral Classification, Diagnostic Diagram.

Apresentamos a primeira espectroscopia de fenda longa para a galáxia HRG 10103, uma galáxia peculiar do tipo $\mathrm{Sa}(\mathrm{r})$ vista de frente com uma estrutura elíptica assimétrica. O principal objetivo deste trabalho é fornecer a classificação espectral do presente objeto usando os diagramas de diagnósticos 'tradicionais'. Contudo, também apresentamos um diagnóstico envolvendo a conhecida razão de linha-de-emissão R23, usualmente utilizada para estimar a razão de abundância $O / H$. A ideia é construir uma distinção melhor entre as AGNs de linha-estreita e as galáxias H II. Os espectros foram obtidos em dois observatórios (OPD-LNA/MCT e Gemini-Sul) e inclui algumas das mais importantes linhas de emissão para o diagnóstico de ionização. Baseando-se nos espectros observados, HRG 10103 é uma galáxia Seyfert 2 com valores de razões-de-linha típicas no intervalo óptico. Nós estimamos um desvio para o vermelho nuclear de $z=0.039$. Também apresentamos os valores de desvio para o vermelho resultantes como uma função da distância do núcleo. A redução dos dados espectroscópicos foi realizada utilizando o pacote GEMINI.GMOS bem como os procedimentos padrões da IRAF.

Palavras-chaves: Espectroscopia de Fenda Longa, Galáxia Peculiar, Classificação Espectral, Diagrama de Diagnóstico. 


\section{INTRODUCTION}

There are some galaxies whose structure or emission is different from normal elliptical, spiral, or lenticular galaxies but is also not irregular in the sense of types $I m$ and Irr II; they are referred to as "peculiar" galaxies. Sometimes their peculiar morphologies are the result of interactions with neighboring galaxies. Some galaxies are distinguished by their strong radio and no thermal emission and optical emission lines; these are called "active" galaxies.

In this work, we present the first longslit spectroscopy for the galaxy HRG 10103, a Sa(r) type peculiar galaxy seen face-on with an asymmetrical elliptical structure. The aim of the current study is to describe the main physical properties of this object and also discuss possible evidences of gravitational interaction.

The spectra obtained in two observatories (Gemini South and OPD-LNA/MCT) shows a variety of interesting features and we have used diagnostic diagrams to classify this object as a Seyfert 2 galaxy, at a redshift of $11791 \pm 14$, corresponding to a distance of $158.36 \mathrm{Mpc}(H 0=$ $73 \mathrm{~km} \mathrm{~s}^{-1} \mathrm{Mpc}^{-1}$. Table I gives the journal of some parameters.

\section{SPECTROSCOPIC OBSERVATIONS}

Longslit spectroscopy were obtained using the Boller and Chivens spectrograph attached on the 1.6-m OPD Telescope. The configuration was a 3.0-arcsec-wide longslit centred on the optical peak and oriented at position angle 60 (see Figure 1). The detector used was CCD 101 with $1024 \times 1024$ pixels, and a 600 lines $\mathrm{mm}^{-1}$ grating, blazed at $6081 \AA$, which provides a dispersion of $88.23 \AA \mathrm{mm}^{-1}$. The scale of the frames on the spatial direction was 1.0 arcsec pixel $^{-1}$. The spectral resolution was matched to the $2.12 \AA$ pixel $^{-1}$, yielding an effective res-

\section{DISCUSSION AND CONCLUSION}

The nuclear spectrum for both observatories olution of about $4.0 \AA$ (FWHM) and covering the $4979-7030 \AA$.

The observation was also carried out with the Gemini Multi-Object Spectrograph at Gemini South, as part of poor weather program GS-42007A-Q-72. The grating B600+G5323 centered at $501.1 \mathrm{~nm}$ was used with a longslit 1.0 arcsec wide by 375 arcsec long. The data were binned by 4 in the spatial dimension and 2 in the spectral dimension producing a spectral resolution of $\pm 4.3 \AA$ (FWHM) sampled at $0.68 \AA$ pixel $^{-1}$. The seeing throughout the observations was 1.5 arcsec and the binned pixel scale was $0.145 \operatorname{arcsec}_{\text {pixel }}{ }^{-1}$. The wavelength range was $3560-5650 \AA$. A photometric standard LTT 4816 was also observed using the same experimental set up.

\section{SPECTRAL ANALYSIS}

This galaxy includes some of the most important emission lines for ionization diagnostics: $\mathrm{H} \beta,[\mathrm{OIII}] \lambda 5007,[\mathrm{OI}] \lambda 6300, \mathrm{H} \alpha$, $[\mathrm{NII}] \lambda 6583,[\mathrm{SII}] \lambda \lambda 6716,6731$. The strengths of the detectable emission lines after appropriate dereddening, as well as their equivalent widths, are presented in Table I. These lines intensities and positions were determined by fitting Gaussians to observed profiles. Stellar absorption features are presented as well.

We have used the Balmer decrement $(\mathrm{H} \alpha) /(\mathrm{Hbeta})$ to derive the reddening correction. We consider an intrinsic ratio of $\mathrm{I}(\mathrm{H} \alpha) / \mathrm{I}(\mathrm{H} b e t a)$ of 3.1 for AGN. The observed $\mathrm{F}(\mathrm{H} \alpha) / \mathrm{F}(\mathrm{Hbeta})$ was 5.20 ; thus, the extinction $\mathrm{E}(\mathrm{B}-\mathrm{V})$ was estimated to be $0.485 \mathrm{mag}$.

To map the gas kinematics, we have averaged together the central wavelength of Gaussians which we had fitted the emission lines $\mathrm{H} \beta,[\mathrm{OIII}] \lambda 5007,[\mathrm{OI}] \lambda 6300, \mathrm{H} \alpha,[\mathrm{NII}] \lambda 6583$, $[\mathrm{SII}] \lambda \lambda 6716,6731$. Figure 4 gives the heliocentric velocities. Figure 5 gives a distribution of the observed flux for emission-line ratios.

are presented in the Figures 2(OPD/LNA) and 


\begin{tabular}{|c||c||c||c||c||c||c|}
\hline & $\begin{array}{c}\text { Exp. Time } \\
(\mathrm{s})\end{array}$ & $\begin{array}{c}\text { PA } \\
(0)\end{array}$ & $\begin{array}{c}\text { Seeing } \\
(\operatorname{arcsec})\end{array}$ & Airmass & S/N & $\begin{array}{c}\text { Window } \\
\text { centre }\end{array}$ \\
\hline \hline OPD/LNA & 1200 & 6 & 1.5 & 1.332 & 18 & Nucleus \\
Gemini South & 1200 & 6 & 1.5 & 1.348 & 22 & Nucleus \\
\hline
\end{tabular}

\begin{tabular}{|c||c||c||c||c||c||c|}
\hline & $\begin{array}{c}\alpha \\
(\mathrm{h} \mathrm{m} \mathrm{s})\end{array}$ & $\begin{array}{c}\delta \\
\left({ }^{\prime}{ }^{\prime \prime}\right)\end{array}$ & $\begin{array}{c}\mathrm{v} \\
\left(\mathrm{km} \mathrm{s}^{-1}\right)\end{array}$ & $\begin{array}{c}\text { D, d } \\
(\operatorname{arcmin})\end{array}$ & $\begin{array}{c}\text { Mag } \\
(\text { Filter })\end{array}$ & Type \\
\hline \hline NASA/IPAC & 165820.9 & -632604 & $\begin{array}{c}11779 \pm \\
45\end{array}$ & - & $\begin{array}{c}15.4 \\
(\mathrm{R})\end{array}$ & $\mathrm{Sa}(\mathrm{r})$ \\
\hline
\end{tabular}

TABELA I: Basic paremeters

\begin{tabular}{|c||c|c|c|c|}
\hline Ion & OPD-obs $(\mathrm{EW} \AA)$ & OPD-corr $(\mathrm{EW} \AA)$ & Gem-obs $(\mathrm{EW} \AA)$ & Gem-corr $(\mathrm{EW} \AA)$ \\
\hline$[\mathrm{H} \mathrm{II}] \lambda 3727$ & - & - & $6.58 \pm 0.88(12.54)$ & $21.9 \pm 0.53(13.48)$ \\
\hline $\mathrm{H} \beta \lambda 4861$ & $1.19 \pm 0.68(6.27)$ & $2.40 \pm 0.81(6.20)$ & $2.06 \pm 0.51(1.27)$ & $9.15 \pm 1.11(1.35)$ \\
\hline$[\mathrm{O} \mathrm{III}] \lambda 4959$ & $3.86 \pm 0.96(18.39)$ & $8.67 \pm 1.12(24.06)$ & $7.77 \pm 1.03(17.06)$ & $34.86 \pm 1.37(18.02)$ \\
\hline$[\mathrm{O} \mathrm{III}] \lambda 5007$ & $11.90 \pm 2.54(55.6)$ & $25.15 \pm 2.69(65.48)$ & $23.38 \pm 1.89(40.66)$ & $102.51 \pm 5.63(47.49)$ \\
\hline$[\mathrm{O} \mathrm{I}] \lambda 6300$ & $0.35 \pm 0.09(1.46)$ & $0.95 \pm 0.26(2.52)$ & - & - \\
\hline$[\mathrm{N} \mathrm{II}] \lambda 6548$ & $1.89 \pm 0.42(13.19)$ & $3.24 \pm 0.74(13.14)$ & - & - \\
\hline $\mathrm{H} \alpha \lambda 6563$ & $4.36 \pm 0.87(22.64)$ & $7.31 \pm 0.81(22.96)$ & - & - \\
\hline$[\mathrm{N} \mathrm{II}] \lambda 6583$ & $5.68 \pm 1.08(30.01)$ & $9.41 \pm 0.95(30.09)$ & - & - \\
\hline$[\mathrm{S} \mathrm{II}] \lambda 6716$ & $2.75 \pm 0.95(15.07)$ & $4.45 \pm 1.91(14.99)$ & - & - \\
\hline$[\mathrm{S} \mathrm{II}] \lambda 6731$ & $1.40 \pm 0.78(7.69)$ & $2.32 \pm 1.02(7.88)$ & - & - \\
\hline
\end{tabular}

TABELA II: Emission-lines intensities. Observed and reddening-corrected fluxes in units of $10^{-16}$ erg $\mathrm{cm}^{-2} \mathrm{~s}^{-1} \AA^{-1}$.

\begin{tabular}{|c|c||c||c||c||c|c|c|}
\hline & $\mathrm{H} \alpha / \mathrm{H} \beta$ & {$[\mathrm{O} \mathrm{III]} / \mathrm{H} \beta$} & {$[\mathrm{N} \mathrm{II}] / \mathrm{H} \alpha$} & {$[\mathrm{O} \mathrm{I}] / \mathrm{H} \alpha$} & {$[\mathrm{S} \mathrm{II}] / \mathrm{H} \alpha$} & {$[\mathrm{O} \mathrm{II}] / \mathrm{H} \beta$} & $\mathrm{R}_{23}$ \\
\hline \hline OPD/LNA & 3.05 & 10.48 & 1.29 & 0.13 & 0.93 & - & - \\
\hline \hline Gemini South & - & 11.20 & - & - & - & 2.39 & 1.24 \\
\hline
\end{tabular}

TABELA III: Emission-lines ratios.

3 (GMOS Gemini South). This object was classified as a Seyfert 2 galaxy, with narrow emission lines and $\lambda 6583 / \mathrm{H} \alpha=1.29$. A $\lambda 6300$ emission line is observed with $\lambda 6300 / \mathrm{H} \alpha=0.13$.

The emission-line intensity ratio $R_{23}=$ $([\mathrm{OII}] \lambda 3727+[\mathrm{OIII}] \lambda 4959+[\mathrm{OIII}] \lambda 5007) / \mathrm{H} \beta$ seems effectively to be a very interesting criterion allowing to make a better discrimination between the Seyfert 2 and both the H II galaxies and the LINERs, relatively to the intensity ratio $[\mathrm{O}$ III $] \lambda 5007 / \mathrm{H} \beta$ used in the diagnostic diagrams of Veilleux \& Osterbrock [13].

Figure 2 shows the variation of emission-line rations as a function of distance from the nucleus. All the emission-line ratios show an approximately symmetric behavior on both sides of the nucleus up to \pm 4 arcsec. [NII] $/ \mathrm{H} \alpha$ seems not to vary much, while $[\mathrm{SII}] / \mathrm{H} \alpha$ and $\mathrm{H} \alpha / \mathrm{H} \beta$ show a similar trend. On the other hand, $[\mathrm{O}$ $\mathrm{III}] / \mathrm{H} \beta$ decreases, indicating a higher excitation, also reveled and consistent with the $\mathrm{E}$ (B$\mathrm{V})$ values. $[\mathrm{OI}] / \mathrm{H} \alpha$ show an symmetric behav- 
ior on both sides of the nucleus.

\section{Acknowledgments}

The authors are very grateful to the staff of
Observatório do Pico dos Dias (LNA/MCT), for their assistance during the observations and to the Gemini Observatory.

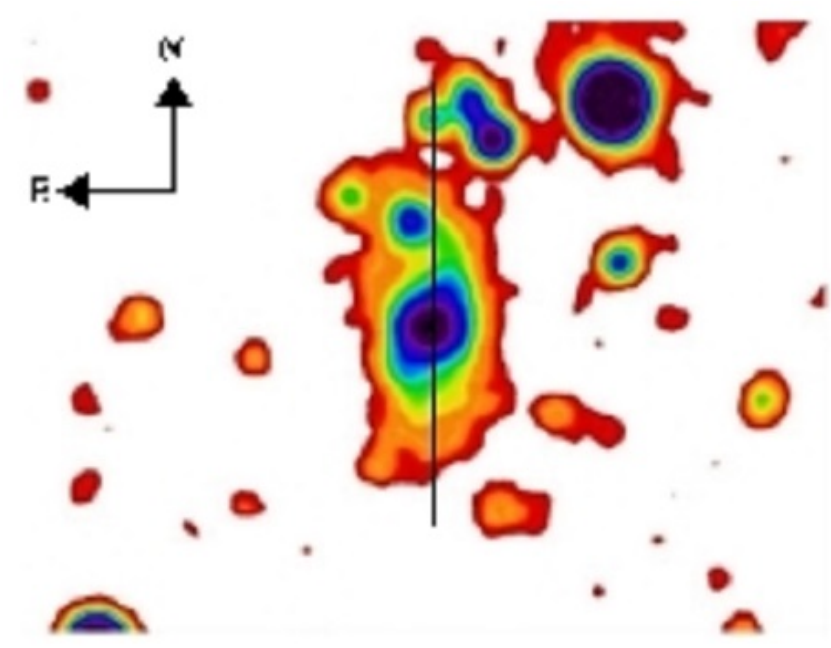

FIGURA 1: Optical image taken from DSS with the slit position overlaid (very similar for both observational runs). The original image has been enhanced to highlight some substructures.

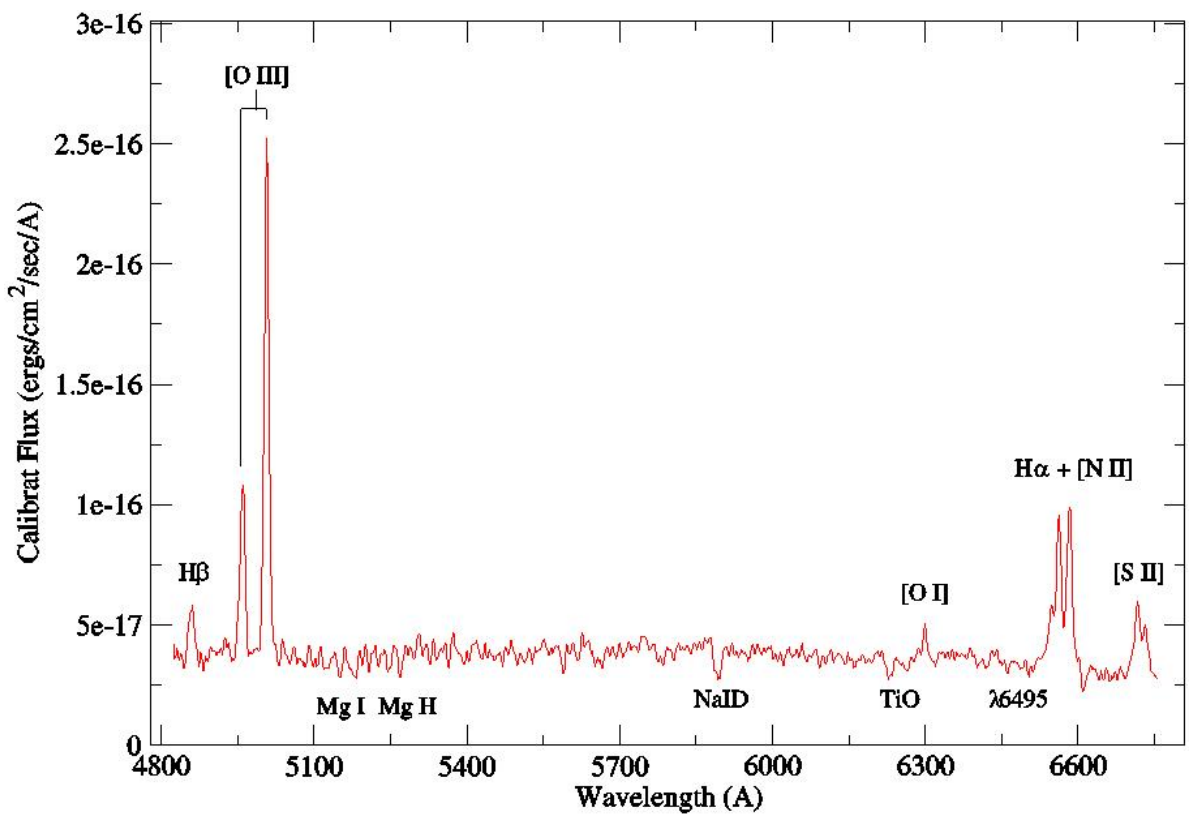

FIGURA 2: Nuclear spectrum: OPD/LNA. 


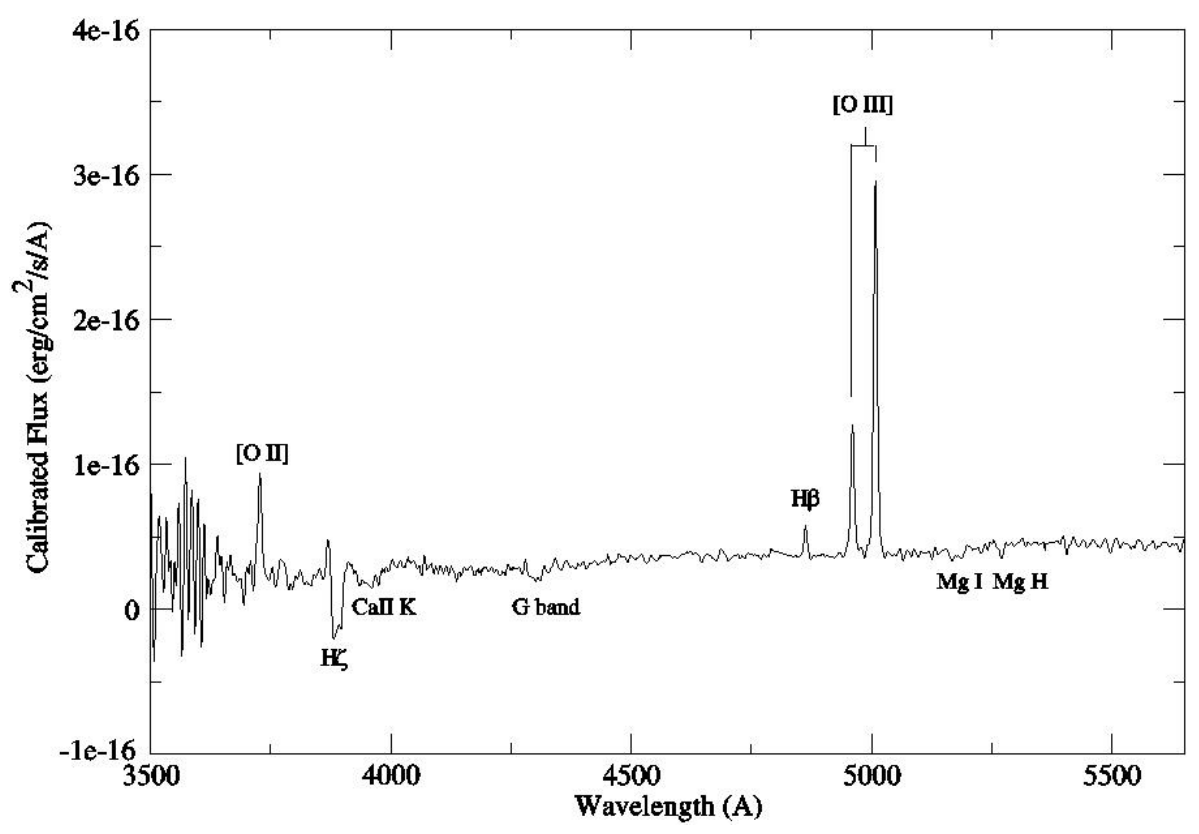

FIGURA 3: Nuclear spectrum: GMOS Gemini.

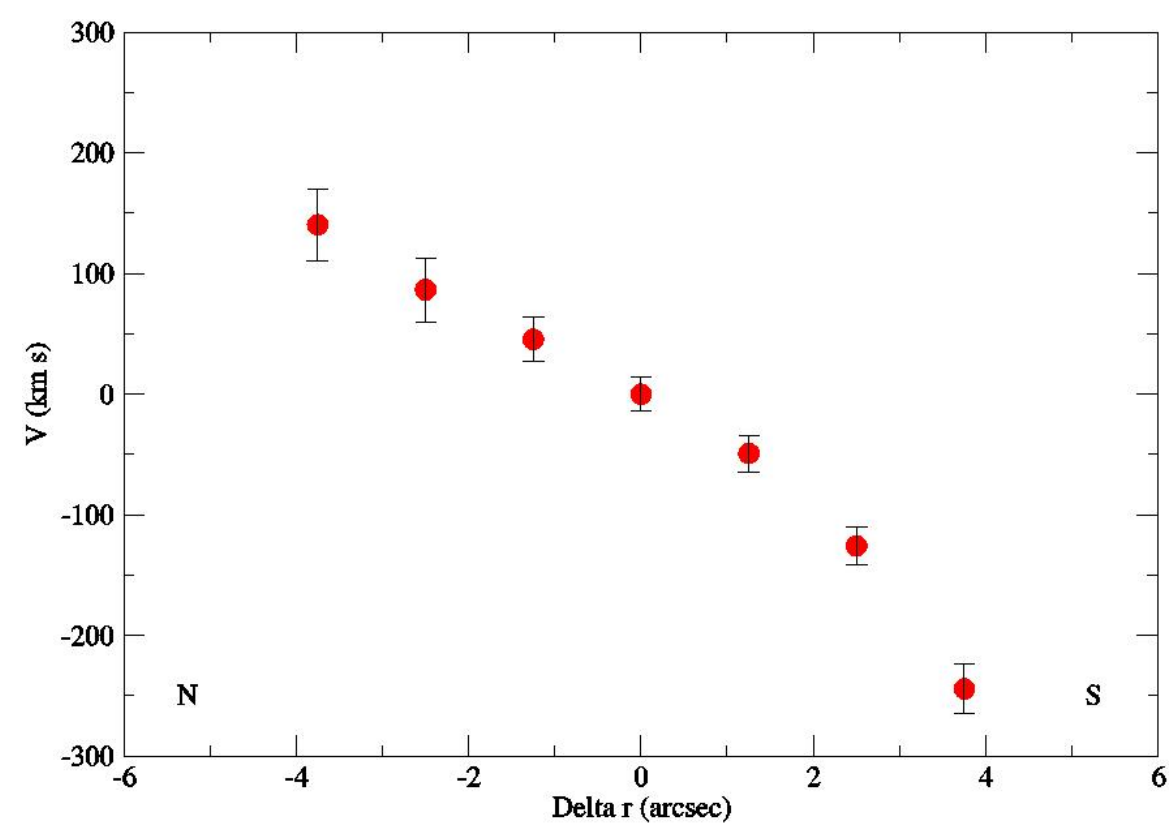

FIGURA 4: Heliocentric velocities from OPD/LNA. 


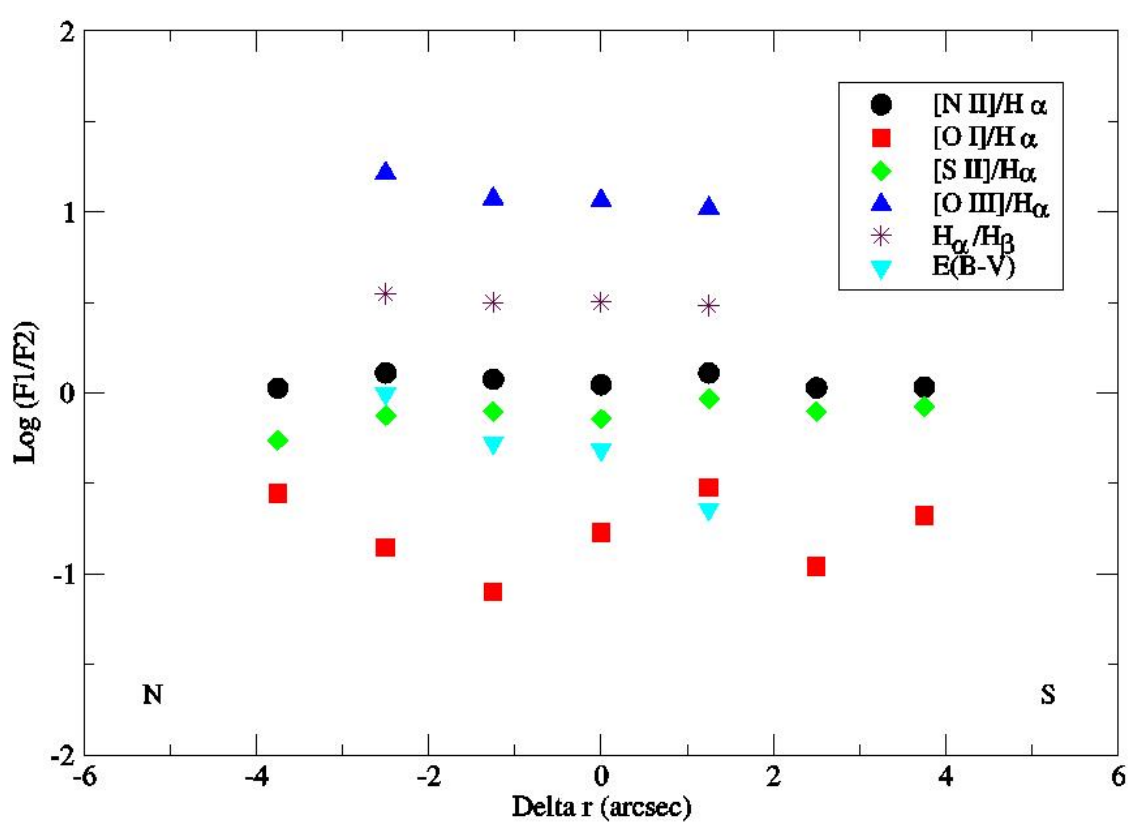

FIGURA 5: Observed emission-line ratios and $\mathrm{E}(\mathrm{B}-\mathrm{V})$ values as function of the distance from the nucleus. Calibrated flux: OPD/LNA.

[1] A. Alonso-Herrero, M.J. Rieke, G.H. Rieke, J.C. Shields. ApJ 530, 688 (2000).

[2] J.A. Baldwin, M.M. Phillips, R. Terlevich. PASP 93, 5 (1981).

[3] M. Brocklehurst. MNRAS 153471 (1971).

[4] A. Constantin, M. Vogeley. ApJ 650, 727 (2006).

[5] M. Faúndez-Abans, M. de Oliveira-Abans. A \& AS 129, 357 (1998).

[6] A.V. Filippenko, R. Terlevich. ApJ L79, 397 (1992).

[7] A.C. Gonçalves, M.P. Véron-Cetty. A \& AS 135, 437 (1999).

[8] L.C. Ho, A. Filippenko, W.L.W. Sargent.
ApJS 112, 315 (1997).

[9] L.C. Ho, A. Filippenko, W.L.W. Sargent. ApJ 487, 568 (1997).

[10] L.J. Kewley, B. Groves, G. Kauffmann, T. Heckman. MNRAS 372, 961 (2006).

[11] D.E. Osterbrock, G.J. Ferland, Astrophysics of Gaseous Nebulae and Active Galactic Nuclei (2nd Edition). Mill Valley: University Science Books (2006).

[12] W. Vacca, P. Conti. ApJ 401, 543 (1992).

[13] S. Veilleux, D.E. Osterbrock. ApJS 63, 295 (1987). 